\title{
Financiamento da seguridade social brasileira: uma história de conflitos
}

\section{Resumo}

$O$ presente artigo aborda a fragilidade do esquema de financiamento da Seguridade Social (Assistência Social, Previdência e Saúde), principalmente, ao longo da década de 90. A análise empreendida aponta os principais momentos em que a "disputa" pelos recursos da Seguridade Social fragilizaram o conceito que lhe dá fundamento: aquele inspirado sob a idéia da universalidade. Particularmente, há uma discussão sobre a instabilidade do financiamento da área da saúde pública. $\mathrm{O}$ artigo está organizado em quatro partes: a primeira, trata do conteúdo da seguridade social, adotada na Constituição Federal de 1988; a segunda parte, diz respeito à relação entre a crise da previdência social e o financiamento da saúde; a terceira, refere-se, especificamente, a insuficiência do financiamento do Sistema Único de Saúde (SUS); e por fim, a quarta parte, discute o comportamento dos recursos da Seguridade Social no ano de 1999. Ao final, o artigo chama a atenção para o fato de que as tensões entre as diversas áreas da Seguridade Social podem diminuir, desde que haja um crescimento econômico sustentado no País.

\section{Abstract \\ The present article discusses the weakness of Social Security financing (Social Assistance, Security and Health), mainly, during the ninety decade. Its analysis deals with the principal moments in which the "dispute" of Social Security resources has weakened the concept that is based upon: the one}

inspired in the idea of universal principles. Particularly, there is a discussion about the instability of Public Health Financing. The article is organized in four parts: firstly, it points out the Social Security concept which has been adopted in the 1988 Federal Constitution; secondly, it deals with the relationship between the social security crisis and health financing system; thirdly, it refers, specifically, to the problematic SUS financing system and; lastly, in the fourth part, it discusses the development of Social Security resources in the year of 1999. Finally, the article pays attention to the fact that the dispute among the different areas in Social Security field could diminish since a susteinable economic development in this country exists.

\section{Introdução}

Diversos especialistas da área de políticas públicas analisam, a partir do enfoque institucional e da execução de ações e serviços descentralizados, que o sistema de proteção social consolidou-se e expandiu-se ao longo dos anos 90. Com menor grau de atenção, é abordada a fragilidade de seu financiamento, principalmente levando-se em conta o conceito de Seguridade Social.

Os anos 90 foram marcados pela falta de re. soluções dos problemas macroeconômicos e de um projeto de crescimento sustentado. A permanência desse quadro definiu o não encaminhamento de soluções para a questão do financiamento da Seguridade Social. Todas as atenções estavam voltadas para a adoção de políticas monetárias ditas neoliberais, onde tinha

\footnotetext{
*Doutora em Economia. Coordenadora do Curso de Ciências Econômicas das Faculdades Integradas "Campos Salles". Professora associada do Departamento de Economia da PUC/SP.

**Doutorando em Ciências Econômicas. Mestre em Relações Internacionais. Bacharel em Administração de Empresas. Professor do Curso de Ciências Econômicas das Faculdades Integradas "Campos Salles", da Faculdade de Economia da FAAP e técnico do CEPAM.
} 
lugar a liberalização e a abertura comercial, bem como a prática de taxas de juros elevadas. Como sabemos, essas políticas resultaram não só no aumento do déficit público, como em recessão e redução progressiva das receitas, inibindo os investimentos e provocando um nível de desemprego nunca antes visto. A economia funcionou de acordo com a lógica do que Keynes chamou de economia cassino ${ }^{1}$, onde a dominância financeira acaba por impor uma grande instabilidade econômica. A persistência dessa lógica e das políticas adotadas pelas autoridades econômicas não permitiram que o financiamento do conjunto das áreas que compõem a Seguridade Social (Assistência Social, Previdência e Saúde) fosse tratado com o devido cuidado que a situação exigia, sobretudo por ser tratar de instrumento fundamental para a sustentação da demanda efetiva.

Pode-se pensar que esses constrangimentos condicionem o abandono definitivo do conceito de Seguridade Social criado na Constituição Federal e, por conseqüência, de suas bases de financiamento, colocando em pauta qualquer tipo de sistema de proteção social que não seja aquele inspirado sob a idéia da universalidade? $\mathrm{Na}$ tentativa de contribuir para o esclarecimento dessa indagação, este artigo procura apontar os principais momentos em que a "disputa" pelos recursos da Seguridade Social fragilizaram o conceito que lhe dá fundamento.

\section{A Constituição de 1988 e a Seguridade Social}

A partir da Constituição Federal de 1988, o Brasil avançou na consagração de novos direitos sociais e princípios de organização da política social, os quais, pelo menos em nível das definições, modificaram alguns pilares básicos do sistema anterior de proteção social. Influenciada pelo ambiente político-social da abertura e com um discurso de que era preciso resgatar a enorme dívida social brasileira herdada do regime militar, a Constituição procurou garantir direitos básicos e universais de cidadania, estabelecendo o direito à Saúde, Assistência Social e Previdência em um capítulo específico da Seguridade Social.

Tendo em vista os novos direitos introduzidos na área previdenciária e a universalização da saúde, a Constituição de 1988 preocupou-se em ampliar os recursos destinados ao financiamento da Seguridade Social. Assim, além das fontes tradicionalmente utilizadas pelo antigo SINPAS, foi criada a Contribuição sobre o Lucro Líquido da Pessoa Jurídica (CSLL) e incorporada a receita do Finsocial (hoje Cofins) para seu único uso. A incorporação dessas novas fontes também visava tornar o financiamento menos dependente das variações cíclicas da economia. Contudo, estudos posteriores indicaram que as novas fontes são também bastante sensíveis ao desempenho da economia.

De qualquer maneira, a diversificação das fontes poderia melhorar sensivelmente o aporte de recursos para a Seguridade. No entanto, não foi o que ocorreu. Em 1989, primeiro ano após a instituição da Seguridade, além de seu orçamento não ter sido elaborado, os novos recursos, que deveriam integrá-lo, foram abusivamente desviados para financiar outras atividades. Foi assim que $99,92 \%$ dos recursos da Contribuição sobre o Lucro foram destinados para o pagamento das despesas com pessoal e administração, o que deveria ter sido financiado através de recursos fiscais. Já o Finsocial foi direcionado para as despesas dos Encargos Previdenciários da União (pensões e aposentadorias do funcionalismo público federal, benefícios de regime não incluso na Seguridade Social). Embora a situação tenha melhorado em 1990, apenas 58\% da arrecadação da Contribuição sobre o Lucro foram destinados ao financiamento das áreas da Seguridade Social. No caso do Finsocial, o uso não passou de $60 \%$.

A Constituição de 1988 dispunha, ainda, em suas disposições transitórias, que pelo menos 30\% do total de recursos da Seguridade Social, com exceção da receita do PIS/Pasep que é vinculada $^{2}$, deveriam ser destinados à área da Saúde,

Para uma discussão desses resultados no Brasil e na América Latina, ver Salama (2000).

${ }^{2} \mathrm{O}$ PIS/Pasep destina-se ao financiamento do seguro-desemprego e ao pagamento do abono PIS/Pasep. Além disso, 40\% de 
enquanto não fosse aprovada sua lei orgânica. Dessa forma, manteve-se relativamente alta a transferência de recursos de contribuição de empregados e empregadores para a Saúde, por exemplo.

Contudo, com a aprovação da Lei Orgânica da Saúde, ao final de 1990, foi possível , ao então Ministério da Previdência Social, reduzir o volume desse repasse. A transferência para o Ministério da Saúde, que representava 33,1\% da receita de contribuições em 1991, passou para apenas 20,9\% em 1992. Para 1993, a Lei de Diretrizes Orçamentárias (LDO) estipulava que $15,5 \%$ do total arrecadado a título de contribuições deveriam ser repassados para a área da Saúde.

A rigor, durante esses anos, houve praticamente uma especialização das fontes da Seguridade Social: os orçamentos destinaram a maior parte dos recursos do Finsocial para a Saúde, da Contribuição sobre o Lucro para a Assistência e das contribuições de empregados e empregadores para a Previdência Social. Essa prática tornou-se rapidamente muito cara para a Saúde.

\section{A Crise da Previdência Social e o Financiamento da Saúde}

Apesar do disposto na LDO, não foi efetuado nenhum repasse para a Saúde em maio de 1993. Em junho, foram transferidos cerca de 4,6\% da receita de contribuições do mês. Cessaram-se, a partir daí, todas as transferências. A decisão de não efetuar o repasse para o Ministério da Saúde foi tomada com a aquiescência do então presi- dente da República. A justificativa alegada foi que a Previdência Social estava apresentando problemas de caixa de tal ordem que, caso as transferências prosseguissem, acabaria por encerrar o ano com déficit. Frente à situação financeira criada, o presidente da República decretou situação de calamidade pública na área da Saúde. O problema somente foi resolvido, quando foram liberados recursos para o INAMPS, sob a forma de empréstimo do Fundo de Amparo do Trabalhador (FAT). Tal como ocorreu em empréstimo anterior, o Tesouro Nacional responsabilizou-se pela operação através da emissão de Notas do Tesouro Nacional. O empréstimo realizado foi para 6 meses, com juros de $5 \%$ ao ano e correção pela TR.

De fato, a Previdência Social teria apresentado déficit em 1993, caso tivesse prosseguido com os repasses. A disponibilidade, que registrou ao final do ano, era suficiente apenas para honrar 4,3 meses de transferências para a Saúde. A fragilidade da situação previdenciária teve duas causas básicas: o fraco desempenho da arrecadação das contribuições e o aumento significativo da despesa com benefícios.

A medida adotada pelo governo federal de cessar o repasse para a área da Saúde foi bastante criticada por vários analistas. Segundo eles, o governo perdeu a oportunidade de demonstrar para a sociedade que o conjunto da Seguridade Social apresentava dificuldades de financiamento e que essas se originavam na Previdência Social $^{3}$. A escolha política realizada deixou a descoberto a Saúde e os problemas daí decorrentes auxiliaram para denegrir sua imagem junto à opinião pública.

\footnotetext{
sua arrecadação são transferidos ao BNDES para serem utilizados sob a forma de empréstimo às empresas.

${ }^{3}$ Também defendiam que o tratamento das fontes de financiamento da Seguridade Social não é distinto de seu conceito. Em outras palavras, consideravam que, ao ser eleita a cidadania, e não o mérito, como a referência para o direito à proteção social, estabeleceu-se que a sociedade deveria, a cada ano, discutir e definir de que forma seria realizada a partilha do conjunto de receitas previstas para a Seguridade Social. Isso significa dizer que os constituintes se colocaram contra o estabelecimento de vinculação de receitas no interior da Seguridade Social. A única exceção ficou por conta do PIS/Pasep, que passou a ter uso exclusivo do programa seguro-desemprego e do pagamento do abono PIS/Pasep, sendo que 40\% de sua arrecadação é destinada a empréstimos realizados pelo BNDES às empresas.

Dessa forma, quando foi estabelecido o vínculo entre a área previdendiária e as contribuições de empregados e empregadores, em 1993, foi rompido o conceito de Seguridade Social. Para eles, a priorização de áreas no interior da Seguridade Social é uma ação que conceitualmente se opõe à compreensão holística de proteção social.
} 
As dificuldades financeiras da Previdência Social aprofundaram-se nos anos posteriores a 1993, tornando ainda mais difícil o financiamento da área da Saúde. O baixo resultado da receita de contribuições de empregados e empregadores e o aumento da despesa com benefícios, resultou em alteração estratégica da Previdência Social no interior da Seguridade Social. Além de, na prática, ficar definido que as contribuições de empregados e empregadores seriam de uso exclusivo da Previdência, essa passou a avançar sobre as demais fontes da Seguridade Social.

Para se ter uma idéia, em 1997, do total arrecadado pelo Finsocial/Cofins e da Contribuição sobre o Lucro, 33, 6\% foram destinados ao financiamento dos benefícios previdenciários. A destinação dos recursos dessas duas fontes do custeio da Seguridade Social pode ser acompanhada no Quadro 1 (pág. 59), para 1996 e 1997.

Em 1997, a arrecadação da Cofins e da Contribuição sobre o Lucro representaram $21,4 \%$ e $8,6 \%$, respectivamente, do total dos recursos teoricamente disponíveis pela Seguridade Social (Quadro 2 pág 59). Vale esclarecer que $20 \%$ da arrecadação das contribuições eram destinadas ao Fundo de Estabilização Fiscal (FEF - hoje Desvinculação das Receitas da União - DRU), o que, para muitos, significou o rompimento do disposto na Constituição Federal. A criação desse Fundo permitiu que o governo federal dispusesse de parte dos recursos da Seguridade Social, os quais, pela Constituição de 1988, seriam de seu uso exclusivo. Em outras palavras, possibilitou a flexibilização dos recursos, tão ao gosto dos economistas ligados ao mainstream.

O Quadro 2 (pág 59), que apresenta o volume de recursos arrecadados a título de impostos e contribuições, de responsabilidade da Secretaria da Receita Federal e do INSS, destaca o peso das receitas de contribuições no orçamento da União.

O resultado do avanço da Previdência Social sobre os recursos da Seguridade Social foi o com- prometimento das demais políticas, principalmente da área da Saúde, o que será analisado mais adiante neste artigo. $\mathrm{O}$ que vale destacar aqui é que essa situação está diretamente relacionada à política econômica desenvolvida pelo governo federal. Esse, ao definir a estabilização como único objetivo a ser perseguido, colocou a economia refém de juros elevados e de uma moeda sobrevalorizada, de maneira que ficou inviabilizado o crescimento econômico e a geração de empregos. Enquanto a economia não voltar a apresentar taxas expressivas de crescimento e a criar empregos de qualidade, fica comprometido o financiamento do conjunto das áreas da Seguridade Social.

\section{O financiamento do Sistema Único de Saúde (SUS)}

Desde a instituição do Sistema Único de Saúde (SUS), pela Constituição de 1988, a insuficiência de recursos, bem como a ineficiência e a ineficácia de sua utilização, têm estado constantemente em debate. Contudo, é fora de dúvida que a primeira restrição assume principalidade, pois condiciona muitas vezes a eficiência esperada do sistema.

A situação financeira da área da Saúde ${ }^{4}$ é condicionada por dois determinantes: o tratamento concedido à Previdência no interior da Seguridade Social e a política austera implementada pelo governo federal no campo social, decorrente de sua realidade financeira. Como visto anteriormente, desde 1993, a Saúde deixou de contar com os recursos das contribuições de empregados e empregadores, principal fonte de seu custeio, até então. A partir desse momento, a Saúde ficou mais dependente do Tesouro Nacional. Em outras palavras, seu financiamento passou a depender, mais do que antes, da disponibilidade de caixa do Tesouro Nacional e de negociações realizadas junto à esfera econômica do governo federal.

${ }^{4}$ Embora seu financiamento seja composto de recursos das três esferas de governo, estima-se que 78,4\% do gasto realizado em 1997 tenha sido de responsabilidade do governo federal. Essa informação justifica porque a análise aqui realizada está centrada, basicamente, no acompanhamento do gasto em saúde desse nível de governo. 
Apesar da crise provocada pelo não recebimento do repasse das contribuições, o gasto federal registrou aumento em 1993 (Quadro 3 pág 60). O acompanhamento da série histórica permite verificar que houve crescimento do montante de recursos de origem federal, em 1995 e 1997; comparando-se os anos extremos da tabela, o crescimento foi de $28 \%$, o que certamente é muito pouco, dadas as necessidades. Por outro lado, uma leitura um pouco mais apurada indica que, se forem descontadas as despesas financeiras e os restos a pagar ${ }^{5}$, em 1997, o volume de recursos efetivamente disponíveis para as ações e serviços da área da Saúde foi inferior ao de 1995.

Mesmo se for considerado o total de recursos disponíveis para a área da Saúde (incluindo as despesas financeiras e os restos a pagar), ele é considerado insuficiente, de forma que o gasto federal per capita é extremamente baixo, se comparado aos níveis praticados internacionalmente. O Quadro 4 (pág 60) permite acompanhar a evolução do gasto federal entre 1994 e 1997.

Em 1998, o gasto federal com saúde, considerando inclusive as despesas financeiras e com inativos, foi da ordem de $\mathrm{R} \$ 18,9$ bilhões, o que correspondeu a um per capita de $\mathrm{R} \$ 116,82$. De 1997 para 1998, houve um aparente aumento do gasto federal "com saúde" $(7,4 \%)$, o que não significou mais recursos para o setor. Isto é, se forem deduzidos os gastos com a dívida ( $\mathrm{R} \$ 1,9$ bilhões) e com inativos ( $\mathrm{R} \$ 1,7$ bilhões), o gasto totalizará apenas $\mathrm{R} \$ 15,3$ bilhões, correspondendo a uma despesa per capita de apenas $\mathrm{R} \$ 94,57$.

A análise do gasto realizado pelo Ministério da Saúde (MS) indica que a maior parte (57\%) da despesa federal é realizada com assistência médico-hospitalar, tanto de provedores privados como públicos. Essa despesa, comparada à realizada em 1994, aumentou 89\% junto ao sistema
AIH/SIA/SUS e $62 \%$ junto aos hospitais do próprio ministério. Esses crescimentos, tendo em vista a retração de recursos observada para a saúde em geral, indicam como foi forte a perda ocorrida nas demais atividades, em especial naquelas de caráter preventivo. Em 1996, por exemplo, destaca-se a queda de recursos para a produção de vacinas $(-56,63 \%)$, em endemias $(-48,29 \%)$ e malária $(-78,32 \%)$.

No que se refere às fontes de financiamento da saúde pública, já que o MS não poderia mais continuar na política de tomar empréstimos junto ao FAT, o então Ministro Adib Jatene sugeriu e lutou pela criação da Contribuição sobre a Movimentação Financeira (CPMF), que veio a vigorar a partir de 1997. Nesse ano, o volume arrecadado com o CPMF foi de R $\$ 6,909$ bilhões e, em 1998, R\$ 8,08 bilhões. Desses totais, boa parte foi encaminhada ao MS, o que seria de se esperar, já que essa contribuição foi instituída, teoricamente, para financiar a área da Saúde. Apesar disso, em 1997, R\$1,4 bilhão e, em 1998, R\$ 1,6 bilhão, foram destinados a atividades alheias à saúde, através da desvinculação propiciada pela existência do Fundo de Estabilização Fiscal (FEF).

Contudo, o inusitado ficou por conta da compensação realizada pelo governo federal com as demais fontes de contribuições sociais que vinham financiando as ações e serviços de saúde. O Quadro 5 (pág 61) é bastante ilustrativo a esse respeito. Note-se que a entrada de recursos da CPMF foi realizada mediante a redução do aporte da COFINS e da CSLL - Contribuição sobre o Lucro Líquido da Pessoa Jurídica (especialmente em 1998), que passaram a ser transferidas crescentemente para a área previdenciária. Desse modo, alterou-se significativamente a composição das fontes de custeio do Ministério. Não é por acaso, portanto, que a

\footnotetext{
${ }^{5}$ As despesas financeiras referem-se à amortização da dívida contraída junto ao FAT, para fazer frente ao pagamento da rede hospitalar do SUS. Até o momento, foram realizados três empréstimos. Os pagamentos realizados foram de R $\$ 339,2$ milhões em 1994, R \$ 1.531,2 milhões em 1995, R \$ 423,1 milhões em 1996 e R \$ 1.438,7 milhões em 1997. Os restos a pagar referemse a pagamentos de autorizações de internação hospitalar $(\mathrm{AIH})$ e de atendimento ambulatorial que foram postergados para o exercício seguinte. Foram de R \$ 213 milhões em 1994, de R \$ 895,8 milhões em 1995, de R \$ 1.030 milhões em 1996 e de $\mathrm{R} \$ 2.224,3$ milhões em 1997 (em valores em dezembro de 1997).
} 
mídia e os outdoors defendiam que nada mudou na Saúde com a entrada do CPMF.

Os baixos recursos disponíveis para a área da Saúde resultaram que algumas atividades fossem relegadas a um segundo plano, muito embora elas assumam importância estratégica no contexto da saúde e exijam reduzido esforço orçamentário. Desse modo, suas ações sofreram descontinuidade, comprometendo todo o investimento realizado anteriormente ${ }^{6}$. Esse é o caso da erradicação do Aedes Aegypti, mosquito transmissor da dengue e da febre amarela.

Também a maneira como o MS tratou o contingencionamento de parte do orçamento teve impacto negativo em alguns programas, especialmente no controle da dengue e na vigilância sanitária. Esses programas somente tiveram liberados, respectivamente, $57,6 \%$ e $46,4 \%$ dos recursos previstos. O Quadro 6 (pág 61) apresenta os programas ou atividades que tiveram maior percentual de contingencionamento no orçamento do ministério, em 1997 ?

\section{A Seguridade Social no ano de 1999}

É interessante destacar que, apesar da retração econômica, com seus reflexos no mercado de trabalho brasileiro, o conjunto da Seguridade Social não foi deficitário no ano de 1999. Pelo contrário, caso aplicássemos o conceito escrito na Constituição de 1988 e desconsiderássemos o confisco dos 20\% do FEF, teríamos R $\$ 97,1$ bilhões de receita e $\mathrm{R} \$ 80,9$ bilhões de despesa, resultando um superávit de $\mathrm{R} \$ 16,3$ bilhões, o que permitiria que a Previdência respondesse mais tranqüilamente a seus compromissos, enquanto o governo não se dispuser a considerar o combate à informalidade no mercado de trabalho prioritário (Marques e Mendes, 2000).

É claro que em parte esse superávit é definido pelo nível de gasto acordado na Lei Orçamentária. Principalmente na área da Saúde, é sabido que a carência de recursos impede, de maneira geral, a concessão de níveis adequados de atendimento para os demandantes do SUS. A falta de medicamentos, de equipamentos e de pessoal, muitas vezes compromete até mesmo a continuidade de programas como o de assistência aos portadores do HIV e de combate à dengue.

Apesar do resultado expressivo da Seguridade Social, o governo, durante todo o ano de 1999, continuou a confundir a opinião pública. Suas diversas declarações a respeito do déficit da Previdência Social acabaram por facilitar no Congresso a aprovação da Lei no 9.876, que instituiu o "fator previdenciário". Esse fator tem por objetivo definir o valor do benefício em função do tempo de contribuição e da expectativa de sobrevida do segurado no momento do requerimento da aposentadoria. Além disso, a base de cálculo passou a contemplar todo o período de contribuição, o que, por si só, reduz o valor a ser pago.

De maneira geral, portanto, a falta de perspectiva de crescimento continuado da economia brasileira, a manutenção de elevadas taxas de desemprego e a precarização do mercado de trabalho tenderão a dificultar o financiamento da Previdência Social e a tornar cada vez mais tensa a relação dessa área com as demais da Seguridade Social.

\section{Conclusão}

Pelo exposto, a manutenção do conceito de Seguridade Social depende, em primeiro lugar, da partilha de recursos (entre as suas diferentes áreas) ser fruto da decisão democrática da sociedade brasileira, de forma a que o nível de gasto realizado corresponda à prioridade por ela eleita. Em segundo lugar, mas não menos importante, que a economia volte a crescer de forma sustentada. Isso garantiria que, no lugar da prática do corte sistemático das despesas, estivésse-

${ }^{6}$ As ações de combate a vetores, diferentemente de outras, não podem ser interrompidas por força do ciclo biológico do veto. ${ }^{7}$ Para maiores detalhes sobre o financiamento da saúde pública brasileira, ver Marques e Mendes (1999). 
mos promovendo o aumento da receita.

O crescimento econômico sustentado resultaria, de pronto, na queda do desemprego, tanto através do aumento do emprego formal como da ocupação dos chamados autônomos. Essa melhora do mercado de trabalho provocaria aumento da arrecadação da Previdência Social, diminuindo ou eliminando a necessidade de buscar recursos da Cofins e da Contribuição sobre o Lucro
Líquido. Dessa forma, as tensões entre as diferentes áreas da Seguridade Social tenderiam a diminuir, o mesmo ocorrendo na relação Seguridade e Tesouro Nacional. Isso não eximiria, entretanto, da realização de reformas no corpo da Seguridade, principalmente aquelas que redesenhassem a relação público e privado e contemplassem a participação efetiva dos interessados.

\section{Quadro 1}

\begin{tabular}{|l|c|c|c|c|c|c|}
\hline \multicolumn{7}{c|}{ Quadro 1} \\
\hline
\end{tabular}

Fonte: Secretaria da Receita Federal/SIAFI.

\section{Quadro 2}

Receitas Federais arrecadadas pela SRF, contribuições de empregados e empregadores e Receitas da Seguridade Social

\section{RECEITA}

R\$ de dezembro de 1997

Imposto sobre importação

Imposto sobre exportação

5,138

Imposto sobre produtos industrializados

Imposto sobre a renda

Imposto sobre operações financeiras

36,524

Imposto territorial rural

Cofins

0,209

CPMF

19,118

PIS/PASEP

6,909

Contribuição social sobre o lucro

Contribuição plan seg. soc. Servidores

Contribuição para FUNDAF

Outras receitas administrativas

Total da Receita administrativa pela SRF

Demais Receitas

Total das Receitas Federais

Contribuições de empregados e empregadores (1)

TOTAL DOS RECURSOS DA SEGURIDADE SOCIAL

(1) Contribuição arrecadada pelo INSS.

As receitas em itálico integram o orçamento da Seguridade Social. 


\begin{tabular}{|c|c|c|c|c|}
\hline \multicolumn{5}{|c|}{ Quadro 3} \\
\hline \multicolumn{5}{|c|}{ Gasto Público com Saúde nas três esferas de Governo } \\
\hline \multicolumn{5}{|c|}{$1980=100$} \\
\hline ANOS & UNIÃO & ESTADOS & MUNICÍPIOS & TOTAL \\
\hline 1980 & 100 & 100 & 100 & 100 \\
\hline 1981 & 92 & 88 & 86 & 91 \\
\hline 1982 & 99 & 82 & 114 & 97 \\
\hline 1983 & 77 & 76 & 86 & 78 \\
\hline 1984 & 80 & 88 & 100 & 83 \\
\hline 1985 & 92 & 94 & 114 & 94 \\
\hline 1986 & 99 & 112 & 157 & 105 \\
\hline 1987 & 143 & 53 & 143 & 128 \\
\hline 1988 & 135 & -35 & 214 & 111 \\
\hline 1989 & 153 & 71 & 214 & 143 \\
\hline 1990 & 128 & 94 & 200 & 128 \\
\hline 1991 & 107 & 82 & 257 & 113 \\
\hline 1992 & 89 & 106 & 257 & 104 \\
\hline 1993 & 112 & 71 & 243 & 114 \\
\hline 1994 & 99 & - & - & - \\
\hline 1995 & 120 & - & - & - \\
\hline 1996 & 106 & - & - & - \\
\hline 1997 & 128 & - & - & - \\
\hline
\end{tabular}

Fonte: IPEA/CSP e IESP/FUNDAP.

Em 1991/92 e 93, os gastos de estados e municípios são estimativa

\section{Quadro 4}

Gasto Federal com Saúde milhões em dezembro de 1997

\begin{tabular}{|c|c|c|c|c|c|c|}
\hline ANOS & TOTAL 1 & TOTAL 2 & TOTAL 3 & Per capita (a) & \% do PIB (a) \\
\hline 1994 & $13.682,6$ & $13.343,4$ & $13.130,4$ & 89,42 & 2,19 \\
\hline 1995 & $16.562,6$ & $15.031,4$ & $14.135,6$ & 106,82 & 2,06 \\
\hline 1996 & $14.597,0$ & $14.164,9$ & $13.131,9$ & 92,93 & 1,76 \\
\hline 1997 & $17.582,5$ & $16.143,8$ & $13.919,5$ & 109,81 & 2,13 \\
\hline
\end{tabular}

Fonte: IPEA/DIPOS.

(a) calculado com o total 1 total 1 = total geral da área; total 2 = excluídas as despesas financeiras;

total 3 = excluídas as despesas financeiras e restos a pagar. 
Quadro 5

\begin{tabular}{|c|c|c|c|c|c|}
\hline \multicolumn{6}{|c|}{ Distribuição dos recursos do Ministério da Saúde, por fontes } \\
\hline FONTES & 1996 & 1997 & & 1998 & \\
\hline & $\%$ & $\mathrm{R} \$$ correntes & $\%$ & $\mathrm{R} \$$ correntes & $\%$ \\
\hline Recursos Ordinários & - & 115.705 .536 & 0,7 & 1.695 .484 .343 & 9,3 \\
\hline Concursos E Prognósticos & 0,4 & 151.093 .955 & 0,9 & & \\
\hline \multicolumn{6}{|l|}{ Alienação De Bens Apreend.- } \\
\hline Títulos Tesouro - Ref. Divid. Fed. & - & 71.137 .857 & 0,4 & 106.575 .083 & 0,6 \\
\hline Títulos Tesouro - Outr. Aplic. & 3,4 & 460.674 .483 & 2,6 & 9.035 .232 & 0,1 \\
\hline Oper. Crédito Inter. - Moeda & 8,4 & & & & \\
\hline Oper. Crédito Exter. - Moeda & 0,8 & 98.983 .336 & 0,5 & 54.152 .903 & 0,3 \\
\hline Oper. Cred. Ext. - Bens E Serv. & - & & & & \\
\hline Dpvat & 2,1 & 373.691 .240 & 2,1 & 467.794 .977 & 2,5 \\
\hline Contrib. S/Lucro Pessoa Jurídica & 21,1 & 4.244 .174 .023 & 24,1 & 1.333 .329 .326 & 7,7 \\
\hline Cofins & 40,5 & 2.707 .690 .021 & 15,4 & 4.342 .869 .222 & 23,7 \\
\hline Cpmf - $80 \%$ & - & 5.486 .742 .331 & 31,2 & 6.466 .837 .097 & 35,3 \\
\hline Contrib. Plano Seg. Social Servidor & 2,9 & & & 20.138 .000 & 0,1 \\
\hline Doações Intern. Contrap. & 0,3 & 26.259 .435 & 0,1 & & \\
\hline Fef E Fse & 15,3 & 3.360 .834 .683 & 19,1 & 1.909 .087 .600 & 10,4 \\
\hline Receitas De Restos A Pagar & 2,0 & 49.284 .450 & 0,3 & & \\
\hline Rec. Darf Sem Transf. Finn & 2,7 & 439.978 .981 & 2,5 & 459.537 .682 & 2,5 \\
\hline Recursos Diret. Arrecadados & 0,1 & 11.610 .185 & 0,1 & & \\
\hline Trtn - Refinanciamento & & & & 46.931 .456 & 0,3 \\
\hline Trtn - Outras Aplicações & & & & 33.893 .308 & 0,2 \\
\hline Contrapartida Nacional & & & & 11.210 .000 & 0,1 \\
\hline Dívida Amortizada Pela Stn & & & & 1.381 .958 .552 & 7,5 \\
\hline Total De Receitas & 100,0 & 17.597 .860 .522 & 100,0 & 18.338 .834 .781 & 100,0 \\
\hline
\end{tabular}

Fonte: MS

\begin{tabular}{|c|c|}
\hline \multicolumn{2}{|c|}{ Quadro 6} \\
\hline \multicolumn{2}{|c|}{ Percentual de descontingencionamento de alguns Programas do MS } \\
\hline 1997 & $\%$ \\
\hline PROGRAMAS & DESCONTINGENCIADO (1) \\
\hline Sangue e hemoderivados & 3,0 \\
\hline Infra-estrutura de unidades & 20,0 \\
\hline Saneamento básico & 42,7 \\
\hline Carências nutricionais & 27,8 \\
\hline Vigilância sanitária & 46,4 \\
\hline Programa de Leite & 50,0 \\
\hline Erradicação Aedes Aegypti & 57,6 \\
\hline $\begin{array}{l}\text { Fonte: MS/Conselho Nacional de Saúc } \\
\text { (1) Relação entre o Orçamento inicial }\end{array}$ & o valor liberado. \\
\hline
\end{tabular}

REFERÊNCIAS BIBLIOGRÁFICAS

MARQUES, R. M.; MENDES, A. N. Financiamento: a doença crônica da saúde pública brasileira. In: V ENCONTRO NACIONAL DE ECONOMIA DA SAÚDE. Anais . ABRES - Associação Brasileira em Economia da Saúde. Salvador, 1999.

A Proteção Social no primeiro quartel do século XXI: brincando com cenários. In: V ENCONTRO NACIONAL DE ECONOMIA POLÍTICA. Anais. SEP Sociedade Brasileira de Economia Política. Fortaleza, 2000.

SALAMA, P. Do produtivo ao financeiro e do financeiro ao produtivo na Ásia e na América Latina. In: Revista Sociedade Brasileira Economia Política. Rio de Janeiro, n. 6, p. 5-47, jun. 2000. 